Rosana de Paiva Oliveira ${ }^{1}$

Marco Aurélo Faria Elias ${ }^{2}$

Pedro Martins Bellel ${ }^{2}$

SÂmia Martins da Costa Silveira ${ }^{2}$

Vera Maria Peters ${ }^{3}$

Martha de Oliveira Guerra ${ }^{3}$

\title{
Efeito do ultra-som terapêutico em ratas prenhes
}

\author{
Therapeutic ultrasound effect on pregnant rats
}

Artigos originais

Palavras-chave

Terapia por ultra-som/efeitos adversos

Prenhez

Blastocisto

Ratos Wistar

Keywords

Ultrasonic therapy/adverse effects Pregnancy, animal

Blastocyst

Rats, Wistar

\section{Resumo}

OBJETIVO: avaliar o efeito da exposição de ratas ao ultra-som terapêutico na fase de pré-implantação. MÉTODOS: ratas Wistar prenhes foram expostas, na fase de pré-implantação, ao ultra-som de $3 \mathrm{MHz}, 0,6 \mathrm{~W} / \mathrm{cm}^{2}$, com ondas pulsadas (USP) ou ondas contínuas (USC), e os controles (USS) ao ultra-som desligado, por cinco minutos. As ratas foram sacrificadas no 20 dia pós-inseminação. Foram feitas análises bioquímicas e hematológicas. Os animais foram submetidos à necrópsia para identificação de lesões de órgãos internos, remoção e pesagem de fígado, rins e ovários. Foram contados os fetos vivos, malformados, mortos e reabsorvidos. Os fetos, seus cérebros, pulmões, fígados, rins e placentas foram pesados. Os dados obtidos foram analisados por ANOVA - uma via - seguida de teste de Dunnett, qui quadrado ou Kruskal-Wallis $(\alpha=0,05)$. RESULTADOS: as ratas não apresentaram alteração de peso corporal, de órgãos e nem na capacidade reprodutiva, mas houve o aumento dos triglicérides em ambos os grupos, quando comparados ao USS. Os pesos relativos do coração $(0,7 \pm 0,9)$, fígado $(9,8 \pm 0,8)$, rins $(6,2 \pm 0,8)$ e pulmão $(3,8 \pm 0,4)$ dos fetos aumentaram no USC, quando comparados ao coração $(0,6 \pm 0,1)$, fígado $(8,8 \pm 0,5)$, rins $(5,52 \pm 0,5)$ e pulmão $(3,4 \pm 0,4)$ do USS. CONCLUSÕES: no modelo experimental usado, o ultra-som terapêutico não causou toxicidade materna significativa. Ondas pulsadas não alteraram a morfologia fetal, mas as ondas contínuas acarretaram aumento nos pesos relativos do coração, fígado, pulmão e rins dos fetos.

\section{Abstract}

PURPOSE: to evaluate the effect of exposure of female rats to therapeutic ultrasound in the pre-implantation phase. METHODS: pregnant Wistar female rats have been exposed to $3 \mathrm{MHz}, 0.6 \mathrm{~W} / \mathrm{cm}^{2}$ ultrasound, pulsatile ultrasound (PUS) or continuous ultrasound (CUS), and controls, unplugged ultrasound (UUS), for five minutes. The rats were sacrificed at the $20^{\text {th }}$ day post-insemination. Biochemical and hematological analyses have been done. Animals have been submitted to necropsy in order to identify lesions of internal organs, and to remove and weight the liver, kidneys and ovaries. Alive, malformed, dead and reabsorbed fetuses have been counted. RESULTS: the rats have not presented changes in their body and organs weight, and neither in their reproductive capacity, but there has been an increase in triglycerides in the PUS and CUS groups, when compared to the UUS group. The fetuses' relative weights of the heart $(0.7 \pm 0.9)$, liver $(9.8 \pm 0.8)$, kidneys $(6.2 \pm 0.8)$ and lungs $(3.8 \pm 0.4)$ increased in the CUS, when compared to the heart $(0.7 \pm 0.9)$, liver $(9.8 \pm 0.8)$, kidneys $(6.2 \pm 0.8)$ e lungs $(3.8 \pm 0.4)$ of the UUS. CONCLUSIONS: in the experimental model, the therapeutic ultrasound used has not caused meaningful maternal toxicity. Pulsatile waves have not changed fetal morphology, but continuous waves have caused increase in the relative weight of the fetuses' heart, liver, lungs and kidneys.
Centro de Biologia da Reprodução da Universidade Federal de Juiz de Fora - UFJF - Juiz de Fora (MG), Brasil.

' Pós-graduanda do Programa de Pós-graduação em Saúde Brasileira da Universidade Federal de Juiz de Fora - UFJF - Juiz de Fora (MG), Brasil.

${ }^{2}$ Bolsistas de Iniciação Científica do Centro de Biologia da Reprodução (CRB) da Universidade Federal de Juiz de Fora - UFJF - Juiz de Fora (MG), Brasil.

${ }_{3}^{3}$ Pesquisadoras do Centro de Biologia da Reprodução (CRB) da Universidade Federal de Juiz de Fora - UFJF - Juiz de Fora (MG), Brasil.

Auxilio financeiro: Redes Mineiras de Bioterismo - Rede 2824/05 e 2827/05 


\section{Introdução}

O ultra-som é um dos recursos terapêuticos empregados freqüentemente para reabilitação de disfunções dermato-funcionais, como pré-operatório de lipocirurgias, correção de celulites e gordura localizada - terapia procurada, principalmente por mulheres jovens visando correção de disfunções estéticas ${ }^{1}$. Por estarem em plena fase reprodutiva, essas mulheres podem ser expostas à irradiação do ultra-som terapêutico em fases precoces de gestação - habitualmente não percebidas. Lesões do concepto nessa fase do desenvolvimento podem resultar em aborto precoce, que se manifesta por hemorragia vaginal, podendo ser confundido com distúrbio da menstruação ${ }^{2}$.

Os efeitos do ultra-som terapêutico são decorrentes de ação mecânica ou térmica, que aumenta a permeabilidade da membrana celular, altera a difusão de íons, modifica a posição de partículas intra ou extracelulares ou a configuração normal da célula, levando à alteração de suas funções. Além disso, as vibrações sônicas do ultra-som terapêutico produzem micromassagem nos tecidos, que gera calor por fricção, promovendo vasodilatação ${ }^{3}$.

Alguns dos efeitos do ultra-som poderiam ser prejudiciais à morfogênese embrionária, uma vez que as células embrionárias, em processo de diferenciação, dependem da síntese protéica, da segregação de fatores de transcrição e de diversas sinalizações, que são efetuadas através de canais de cálcio, sódio e potássio ${ }^{4,5}$.

Estudos sobre os efeitos do ultra-som terapêutico no desenvolvimento embrionário são antigos e contraditórios. Alguns indicam a ocorrência de mortes ${ }^{6}$, alterações embrionárias in vitro ${ }^{7}$, restrição de crescimento fetal ${ }^{6,8} \mathrm{e}$ baixo peso ao nascer ${ }^{8}$. Outros não relatam alteração no desenvolvimento embrionário ou fetal ${ }^{9}$. Entretanto, a metodologia usada pelos autores, no que se refere à intensidade, frequiência e tipo de onda sonora, ao tempo de exposição e ao período de gestação, variou de autor para autor, não havendo coincidência entre eles, o que talvez explique a disparidade de resultados.

Quanto ao efeito do ultra-som durante a fase tubária do desenvolvimento embrionário, as pesquisas são escassas. Um dos estudos mostrou o efeito do ultra-som em ratas, cujos cornos uterinos foram mergulhados em recipiente com água, no terceiro ou no sexto dia pós-inseminação, não relatando malformações nem restrição do crescimento intra-uterino em fetos de 17 dias $^{10}$. A exposição contínua de ratas ao ultra-som, desde o quarto até ao $20^{\circ}$ dia de prenhez, não causou toxicidade materna, mas com o aumento da intensidade houve alteração da atividade locomotora da prole ${ }^{11}$. Esse resultado não foi confirmado em trabalho semelhante, o qual não se observou efeito embriotóxico?

A exposição de ratas prenhes no dia 3,5 aumentou o número de reabsorções e provocou diferença no peso de fetos vivos, enquanto que no dia 6,5 determinou aumento significativo do número de fetos com redução do peso e comprimento do corpo ${ }^{8}$.

Estudos in vitro com mórula tardia e no início da formação do blastocisto mostraram que a exposição ao ultra-som causa restrição no desenvolvimento embrionário e, quando se aumenta a intensidade, também ocorrem alterações morfológicas ${ }^{7}$. Estes resultados não foram confirmados em experimentos com cultivo de estágios de uma e duas células, mórula e blastocisto, quando não foram observadas anomalias no desenvolvimento do embrião de rato, nem da síntese do ácido nucléico, ao se aplicar ultra-som nos cultivos ${ }^{12}$.

Considerando o uso freqüente da terapêutica estética por mulheres em fase reprodutiva e o risco da exposição ao ultra-som em fases precoces da gestação, o presente estudo teve como objetivo avaliar o desenvolvimento embrionário precoce em ratas expostas ao ultra-som terapêutico.

\section{Métodos}

Foram usadas ratas Wistar, com três meses de idade, nulíparas, pesando entre 150 e $180 \mathrm{~g}$, da colônia do Biotério do Centro de Biologia da Reprodução da UFJF. Durante o experimento, os animais foram mantidos em gaiolas de polipropileno, providas de cama de maravalha selecionada e bebedouros, dispostas em armários climatizados, no qual a troca de ar, a umidade e temperatura são mantidas constantes. Os armários ficam em alojamento com temperatura mantida através de ar condicionado e provido de sistema de iluminação controlada (12 horas claro e 12 horas escuro), conforme previamente descrito ${ }^{13}$.

As fêmeas foram inseminadas com machos de fertilidade comprovada, considerando-se o primeiro dia de gestação aquele em que foi detectada a presença de espermatozóides no esfregaço vaginal.

Constatada a inseminação, as ratas foram aleatoriamente distribuídas em grupos experimentais contendo 15 animais cada, de acordo com o tipo de ultra-som: ultra-som pulso pulsado (USP); ultra-som pulso contínuo (USC); controle, ultra-som simulado (USS), no qual o aparelho ficou desligado. A aplicação foi realizada desde o primeiro até o quinto dia pós-inseminação.

Cada animal foi sedado com $12 \mathrm{mg} / \mathrm{kg}$ de xilazina, via intraperitoneal e, submetido à tricotomia na região abdominal para demarcação da área de aplicação do ultra-som (Ultrasound Plus da marca Advice Master). Em seqüência, foi passado gel condutor no abdome da rata e aplicado o ultra-som com as seguintes características, seguindo-se a rotina do tratamento efetuado na terapêutica humana ${ }^{3}$ : área efetiva de radiação de $0,4 \mathrm{~cm}^{2}$, freqüência de $3 \mathrm{MHz}$, intensidade média temporal média espacial de $0,6 \mathrm{~W} / \mathrm{cm}^{2}$, com um tempo de cinco minutos de aplicação. 
Terminada a aplicação do ultra-som, o gel foi removido do abdome e as ratas transportadas para gaiolas limpas e observadas por 30 minutos e, posteriormente, uma vez ao dia, visando a constatação de alterações clínicas indicativas de estresse, dor ou toxicidade: modificação na deambulação, presença de piloereção, estereotipia, ocorrência de diarréia, cromodacriorréia (secreção vermelha na região ocular), perdas sangüíneas vaginais e óbitos ${ }^{14}$.

Os animais foram pesados no primeiro, terceiro, sexto, nono, $15^{\circ}$ e $20^{\circ}$ dias pós-inseminação. $\mathrm{O}$ consumo de ração foi estimado no segundo, quinto e sexto dias pós-inseminação e após esse período foi medido uma vez por semana, tendo como base a diferença de peso em gramas de ração colocada num dia e sobras obtidas no dia seguinte.

As ratas foram sacrificadas no $20^{\circ}$ dia pós-inseminação, através de exsangüinação por punção cardíaca sob anestesia $(90 \mathrm{mg} / \mathrm{kg}$ de ketamina IM e $10 \mathrm{mg} / \mathrm{kg}$ de xilazina IP). No sangue coletado realizou-se a análise para determinação de: hematócrito, hemoglobina, leucócitos totais, aminotransferase (AST/TGO), alanina aminotransferase (ALT/TGP), colesterol, triglicérides e creatinina. Posteriormente, os animais foram submetidos à necropsia para identificação de eventuais lesões de órgãos internos.

Foram removidos o fígado, rins, ovários, cornos uterinos e ovidutos, pesando-se os três primeiros em balança analítica com precisão de 0,1 mg (modelo AM 220 da marca Master). Cada ovário foi examinado sob estereomicroscópio para contagem do número de corpos lúteos, enquanto que os cornos uterinos foram examinados para contar os fetos vivos, mortos e as reabsorções.

Foram considerados fetos vivos, os que apresentaram movimentos espontâneos após sua remoção dos envoltórios ou movimentos após estímulo ao toque de uma pinça. Os fetos foram examinados sob estereomicroscópio externamente à procura de malformações e em seguida, pesados, do mesmo modo que suas respectivas placentas. Logo, foram submetidos à crioanestesia e autopsiados para remoção e pesagem de cérebro, pulmão, fígado e rins.

Os dados obtidos foram processados por análise de variância - uma via (ANOVA) e posteriormente ao teste de Dunnett, considerando o grupo USS como controle. Dados não paramétricos foram submetidos aos testes do $\chi^{2}$ ou Kruskal-Wallis. Dados processados pelo Box plot que se mostraram discrepantes foram eliminados, removendo-se o animal da amostra. A hipótese nula foi rejeitada quando $\mathrm{p}<0,05$.

\section{Resultados}

Não foram observados sinais ou sintomas clínicos de toxicidade materna em nenhum dos grupos analisados.
Na Tabela 1, são apresentados os dados referentes ao peso corporal e de órgãos maternos, ao hemograma e as análises bioquímicas dos grupos experimentais estudados. Não houve alteração de peso corporal e de órgãos de ratas nos diferentes grupos experimentais, mas a diferença foi significativa quando a concentração de triglicerídeos foi comparada entre os Grupos USP e USC, em relação ao Grupo USS (controle).

$\mathrm{Na}$ Tabela 2, encontram-se os dados relativos à performance reprodutiva das ratas nos diferentes grupos experimentais, não havendo alteração em relação à performance reprodutiva.

O peso corporal e de órgãos de fetos (média/ninhadas) dos grupos experimentais estudados encontram-se na Tabela 3. Houve diferença significativa em relação aos pesos relativos do coração $(0,7 \pm 0,9)$, fígado $(9,8 \pm 0,8)$, rins $(6,2 \pm 0,8)$ e pulmão $(3,8 \pm 0,4)$ do grupo USC, quando comparados ao coração $(0,6 \pm 0,1)$, fígado $(8,8 \pm 0,5)$, rins $(5,52 \pm 0,5)$ e pulmão $(3,4 \pm 0,4)$ do grupo USS.

Tabela 1 - Peso corporal, peso de órgãos, hemograma e análises bioquímicas de ratas Wistar submetidas, durante os dias um a cinco pós-inseminação, ao ultra-som por ondas contínuas (USC), ultra-som por ondas pulsadas (USP) e ultra-som simulado (USS)

\begin{tabular}{|c|c|c|c|}
\hline \multirow[t]{3}{*}{ Variáveis analisadas } & \multicolumn{3}{|c|}{ Grupos } \\
\hline & USC & USP & USS \\
\hline & Média dp & Média dp & Média dp \\
\hline Peso corporal corrigido $(g) 1$ & $\begin{array}{c}194,7 \\
9,8(14)\end{array}$ & $\begin{array}{c}188,4 \\
12,6(15)\end{array}$ & $\begin{array}{c}191,7 \\
9,9(13)\end{array}$ \\
\hline Ganho de peso (g) & $\begin{array}{c}21,1 \\
6,4(13)\end{array}$ & $\begin{array}{c}22,1 \\
4,4(14)\end{array}$ & $\begin{array}{c}23,8 \\
7,1(13)\end{array}$ \\
\hline Fígado (g) & $\begin{array}{c}9,5 \\
0,8(14)\end{array}$ & $\begin{array}{c}9,4 \\
0,8(15)\end{array}$ & $\begin{array}{c}9,2 \\
0,5(13)\end{array}$ \\
\hline Rins (g) & $\begin{array}{c}1,4 \\
0,2(14)\end{array}$ & $\begin{array}{c}1,4 \\
0,1(14)\end{array}$ & $\begin{array}{c}1,3 \\
0,1(13)\end{array}$ \\
\hline Peso relativo rins (\%) & $\begin{array}{c}0,7 \\
0,1(14)\end{array}$ & $\begin{array}{c}0,7 \\
0,1(14)\end{array}$ & $\begin{array}{c}0,7 \\
0,1(13)\end{array}$ \\
\hline Hematócrito (\%) & $\begin{array}{c}39,1 \\
2,7(14)\end{array}$ & $\begin{array}{c}37,5 \\
2,8(15)\end{array}$ & $\begin{array}{c}38,5 \\
2,8(15)\end{array}$ \\
\hline Hemoglobina ( $g / d L)$ & $\begin{array}{c}12,2 \\
1,1(14)\end{array}$ & $\begin{array}{c}12,2 \\
0,7(15)\end{array}$ & $\begin{array}{c}11,9 \\
0,8(15)\end{array}$ \\
\hline Leucócitos totais(cel/mm3) & $\begin{array}{c}4323 \\
1.254(14)\end{array}$ & $\begin{array}{c}5306 \\
1.351(15)\end{array}$ & $\begin{array}{c}5426 \\
1.555(15)\end{array}$ \\
\hline AST (U/L) & $\begin{array}{c}83,6 \\
62,3(14)\end{array}$ & $\begin{array}{c}35,1 \\
19,1(13)\end{array}$ & $\begin{array}{c}47,1 \\
12,2(14)\end{array}$ \\
\hline ALT (U/L) & $\begin{array}{c}35,8 \\
12,9(14)\end{array}$ & $\begin{array}{c}33,5 \\
7,9(16)\end{array}$ & $\begin{array}{c}32,8 \\
7,6(14)\end{array}$ \\
\hline Colesterol (mg/dL) & $94,7 \pm 25,4(14)$ & $\begin{array}{c}100,0 \\
18,6(16)\end{array}$ & $\begin{array}{c}89,1 \\
6,4(15)\end{array}$ \\
\hline Triglicerídeos (mg/dL) & $\begin{array}{c}236,6 \pm 75,5 \\
(14)^{\star}\end{array}$ & $\begin{array}{c}248,2 \\
125,1(16)^{\star}\end{array}$ & $\begin{array}{c}141,7 \\
51,7(15)\end{array}$ \\
\hline Creatinina (mg/dL) & $0,5 \pm 0,1(13)$ & $\begin{array}{c}0,6 \\
0,1(15)\end{array}$ & $\begin{array}{c}0,5 \\
0,2(14)\end{array}$ \\
\hline
\end{tabular}

'Peso corporal corrigido=peso corporal sem útero, ovários e tubas uterinas. Os resultados estão expressos em média \pm desvio padrão. (N) número de ratas estudadas. Dados extremos, observados no box plot, foram excluídos da análise com * $p<0,05$ em relação ao grupo USS. 
Tabela 2 - Capacidade reprodutiva de ratas submetidas, durante os dias um a cinco, pós-inseminação, ao ultra-som por ondas contínuas (USC), ultra-som por ondas pulsadas (USP) e ultra-som simulado (USS)

\begin{tabular}{|c|c|c|c|}
\hline \multirow[t]{2}{*}{ Variáveis analisadas (n) } & \multicolumn{3}{|c|}{ Grupos } \\
\hline & USC & USP & USS \\
\hline Corpos lúteos & 156 & 177 & 137 \\
\hline Corpos lúteos por rata & $\begin{array}{c}11,1 \\
1,2(14)\end{array}$ & $\begin{array}{c}11,8 \\
1,1(14)\end{array}$ & $\begin{array}{c}11,4 \\
1,6(12)\end{array}$ \\
\hline Implantes & 126 & 155 & 115 \\
\hline Implantes por rata & $\begin{array}{c}9,0 \\
2,1(14)\end{array}$ & $\begin{array}{c}10,3 \\
1,8(15)\end{array}$ & $\begin{array}{c}9,6 \\
1,8(12)\end{array}$ \\
\hline Fetos vivos (\% por grupo) & $\begin{array}{c}101 \\
(80,2)\end{array}$ & $\begin{array}{c}131 \\
(84,5)\end{array}$ & $\begin{array}{c}93 \\
(69,4)\end{array}$ \\
\hline Fetos vivos por rata & $\begin{array}{c}7,2 \\
2,1(14)\end{array}$ & $\begin{array}{c}8,7 \\
1,8(15)\end{array}$ & $\begin{array}{c}7,7 \\
2,3(12)\end{array}$ \\
\hline Fetos mortos (\% por grupo) & $\begin{array}{c}7 \\
(6,48)\end{array}$ & $\begin{array}{c}7 \\
(5,07)\end{array}$ & $\begin{array}{c}11 \\
(10,6)\end{array}$ \\
\hline Reabsorções (\% por grupo) & $\begin{array}{c}17 \\
(5,55)\end{array}$ & $\begin{array}{c}17 \\
(4,52)\end{array}$ & $\begin{array}{c}11 \\
(2,40)\end{array}$ \\
\hline \% de perdas pré-implantação & $\begin{array}{c}25,3 \\
13,8(11)\end{array}$ & $\begin{array}{c}120 \\
8,4(12)\end{array}$ & $\begin{array}{c}20,5 \\
16,7(9)\end{array}$ \\
\hline \% de perdas pós-implantação & $\begin{array}{c}23,7 \\
15,4(12)\end{array}$ & $\begin{array}{c}18,5 \\
11,8(12)\end{array}$ & $\begin{array}{c}24,2 \\
13,1(10)\end{array}$ \\
\hline
\end{tabular}

Os resultados estão expressos em média \pm desvio padrão. $(\mathrm{N})$ números entre parênteses correspondem ao número final de animais em cada grupo. Dados extremos, observados no box plot, levaram à exclusão do animal da análise com $p>0,05$.

\section{Discussão}

Sabe-se que alterações da fisiologia materna são capazes de interferir no desenvolvimento do embrião/feto. São indicativos clínicos de toxicidade, estresse ou sofrimento materno: as alterações do peso corporal, de consumo de ração e sinais como eriçamento dos pêlos, alteração da deambulação no interior da gaiola, movimentos estereotipados, presença de secreção vermelha (cromodacriorréia) ao redor dos olhos, diarréia e sangramento vaginal, entre outros ${ }^{14}$. Nenhum desses indicativos manifestou-se nos grupos experimentais, o que sugere ausência de efeitos lesivos maternos provocados pelas ondas, pulsadas ou contínuas, concordando com resultados de trabalho anterior que também não observou efeitos tóxicos maternos em ratas não anestesiadas, expostas ao ultra-som do quarto ao $19^{\circ}$ dia pós-inseminação ${ }^{11}$. Os exames laboratoriais e hematológicos do presente estudo confirmaram a hipótese de ausência ou baixa toxicidade, pois a única alteração observada foi o aumento dos triglicerídeos nos grupos expostos ao ultra-som. Este aumento pode ser decorrente da modificação da atividade metabólica do tecido adiposo, estimulando a síntese e/ou secreção de adipocitocinas, determinando aumento dos níveis de triglicerídeos ${ }^{15}$.

Níveis sangüíneos inadequados de progesterona ou de estrogênio interferem com a viabilidade do embrião
Tabela 3 - Peso corporal e de órgãos de ninhadas de ratas Wistar submetidas, durante os dias um a cinco pós-inseminacão, ao ultra-som por ondas contínuas (USC), ondas pulsadas (USP) e ultra-som simulado (USS)

\begin{tabular}{|c|c|c|c|}
\hline \multirow{2}{*}{ Variáveis analisadas } & \multicolumn{3}{|c|}{ Grupos } \\
\hline & USC & USP & USS \\
\hline & $1.778,9$ & $1.792,9$ & $1.821,0$ \\
\hline Peso corporal (mg) & 228,6 (14) & $228,6(15)$ & $227,4(15)$ \\
\hline & 467,7 & 461,3 & 464,2 \\
\hline Placenta (mg) & $69,6(14)$ & $49,7(15)$ & $118,2(15)$ \\
\hline & 12,8 & 11,7 & 11,8 \\
\hline Coração (mg) & $2,3(13)$ & $1,1(15)$ & $1,1(13)$ \\
\hline & 178,9 & 162,4 & 163,5 \\
\hline Fígado (mg) & $18,2(13)$ & $18,6(15)$ & $21,4(13)$ \\
\hline & 11,3 & 9,3 & 10,3 \\
\hline Rins (mg) & $32,0(13)$ & $1,0(15)$ & $1,5(13)$ \\
\hline & 69,4 & 58,6 & 62,8 \\
\hline Pulmão (mg) & $9,4(13)$ & $8,3(15)$ & $9,3(13)$ \\
\hline & 110,4 & 103,4 & 104,8 \\
\hline Cérebro (mg) & $7,7(13)$ & $5,8(15)$ & $11,1(13)$ \\
\hline & 0,7 & 0,6 & 0,6 \\
\hline Peso rel coração & $0,9(13)^{*}$ & $0,1(15)$ & $0,1(13)$ \\
\hline & 9,8 & 9,1 & 8,8 \\
\hline Peso rel fígado & $0,8(13)^{*}$ & $0,7(15)$ & $0,5(13)$ \\
\hline Peso rel rins & $\begin{array}{c}6,2 \\
0,8(13)^{*}\end{array}$ & $\begin{array}{c}5,1 \\
0,5(15)\end{array}$ & $\begin{array}{c}5,52 \\
0,5(13)\end{array}$ \\
\hline Peso rel pulmão & $\begin{array}{c}3,8 \\
0,4(13)^{*}\end{array}$ & $\begin{array}{c}3,3 \\
0,3(15)\end{array}$ & $\begin{array}{c}3,4 \\
0,4(13)\end{array}$ \\
\hline
\end{tabular}

Os resultados estão expressos em média \pm desvio padrão. $(\mathrm{N})$ número de ninhadas estudadas. ${ }^{*} p<0,05$ em relação ao grupo ultra-som simulado (USS). Peso rel=peso relativo, obtido pela divisão do peso do órgão pelo peso corporal e multiplicado por 100.

por alterarem o trânsito tubário ${ }^{16}$. Na gestação da rata, os corpos lúteos mantêm-se ativos durante todo o período gestacional e aumentam de volume ${ }^{17}$, garantindo a secreção de progesterona e 20-hidroxi-progesterona ${ }^{18}$. Por serem as estruturas mais volumosas do ovário, os corpos lúteos representam percentuais importantes do peso do órgão do animal prenhe ${ }^{19}$ e, dessa forma, a análise do peso do ovário e do número de corpos lúteos permite uma avaliação indireta dos progestágenos maternos. Como o peso de ovários e o número de corpos lúteos foram semelhantes nos grupos estudados, é sugere-se que os níveis de progestágenos maternos foram semelhantes. Os dados acima indicam que a exposição de ratas, no início da prenhez, ao ultrasom terapêutico, não causou alterações maternas capazes de interferir com o desenvolvimento embrionário.

Durante a prenhez existem três períodos distintos com relação à susceptibilidade do concepto a lesão: pré-diferenciação, diferenciação precoce e avançada ${ }^{20}$, conforme o embrião esteja respectivamente no período de pré-implantação, organogênese ou fetogênese. $\mathrm{O}$ primeiro período ocorre no interior da tuba uterina e compreende as fases de zigoto a blastocisto não eclodido. Em ratas, o primeiro dia pós-inseminação corresponde à fertilização e ao início da primeira divisão da clivagem; no segundo dia, permanecem em fase de dois blastômeros. Ao longo do terceiro dia, encontram-se fases de duas a 
quatro células. Observa-se no quarto dia a fase de mórula e, ocasionalmente, alguns blastocistos em fase inicial de desenvolvimento ${ }^{21,22}$. Entre o terceiro e o quarto dias após a inseminação, inicia-se a blastogênese e, no quinto dia, os blastocistos já migraram para o útero, no qual iniciam o processo de implantação ${ }^{22}$. A exposição das ratas ao ultra-som do primeiro ao quinto dia envolveu, portanto, a maior parte do período de trânsito tubário.

As lesões letais neste período podem causar a morte do concepto antes que ele se implante ou logo no início de sua implantação. Por outro lado, alterações no trânsito tubário, como aceleração ou retardo no transporte do concepto, podem causar dissincronia entre a fase de desenvolvimento e a janela de implantação, o que também resultaria em morte do concepto.

A morte durante a fase precoce do desenvolvimento pode ser inferida pelo menor número de implantes ou fetos no útero, ou pelo aumento do índice de perdas embrionárias, que é estimado considerando-se cada corpo lúteo como indicativo da produção de um ovócito passível de resultar em um zigoto ${ }^{17}$. A diferença entre corpos lúteos e implantes nos cornos uterinos indica, aproximadamente, o número de conceptos "perdidos" 23 .

Os dados obtidos no trabalho mostram que a média de implantes por mãe e o índice de perdas embrionárias pré-implantação foram semelhantes em todos os grupos estudados, portanto, as ondas emitidas no modo pulsado ou contínuo não interferiram com o desenvolvimento das fases pré-diferenciadas. Observaram-se resultados diferentes em um trabalho no qual se relatou aumento de reabsorções, em ratas expostas no dia 3 e no dia 5 de prenhez ao ultra-som pulso contínuo de $3,5 \mathrm{MHz}, 65$ $\mathrm{mW} / \mathrm{cm}^{2}$, durante dez minutos ${ }^{8}$.

Como mencionado anteriormente, os efeitos do ultrasom terapêutico envolvem mecanismos que aumentam a permeabilidade da membrana celular, alteram a difusão de íons, modificam a posição de partículas intra ou extracelulares, ou mesmo a configuração normal da célula, provocando alteração de suas atividades ${ }^{3}$. Além disso, estudos in vitro, em cultivos celulares submetidos ao ultra-som terapêutico, mostraram ruptura de membranas e de macromoléculas e desnaturação de enzimas ${ }^{24}$. Tais alterações poderiam interferir com os processos iniciais das divisões celulares e de difusão de informações intercelulares, determinando malformações.

No presente estudo, não foram observadas malformações externas, e as mortes fetais ocorreram na mesma proporção em todos os grupos experimentais, concordando com resultados apresentados por outros autores, embora usando metodologia diferente ${ }^{9,12}$.
Não foram observadas alterações no peso corporal fetal, concordando com dois trabalhos anteriores ${ }^{10,12}$, mas discordando de Hande e Devi ${ }^{8}$, que mostraram redução do peso e diminuição do comprimento dos fetos de ratas expostas ao ultra-som contínuo em um único dia 3,5 ou 6,5-pós-inseminação.

Os pesos absolutos dos órgãos fetais examinados foram semelhantes, porém, os pesos relativos, exceto o cérebro, foram mais elevados entre os animais submetidos ao ultrasom por ondas contínuas, indicando maior crescimento desses órgãos. É importante reiterar que os pesos corporais foram semelhantes, portanto o maior crescimento dos órgãos não aconteceu em função do peso corporal.

Embriões de ratas expostos in vitro ao ultra-som contínuo, na fase de mórula tardia e no início da formação do blastocisto apresentaram retardo no desenvolvimento embrionário e alterações morfológicas ${ }^{7}$. No presente estudo, a exposição foi in vivo, ao longo do processo de desenvolvimento compreendido entre fertilização e final do desenvolvimento do blastocisto, portanto, qualquer alteração observada deve ter ocorrido em nível molecular ou de genoma, já que ainda não existe tecido desenvolvido. Uma hipótese para explicar tais resultados seria a de que o ultra-som, de alguma forma, poderia reduzir o processo de apoptose no maciço celular interno e favorecer o crescimento de alguns órgãos fetais, sem interferir com o crescimento global, visto que já foi demonstrado que o maciço celular interno e o trofectoderma têm diferente susceptibilidade ao processo de apoptose ${ }^{4}$.

Novamente, as informações disponíveis na literatura sobre o efeito do ultra-som terapêutico no desenvolvimento embrionário não permitem comparações, visto que os experimentos têm metodologia diversa quanto a tempos de exposição, tipo de pulso, intensidade e freqüência, sendo alguns, inclusive, incompatíveis com a realidade clínica.

No presente estudo, procurou-se um modelo experimental que se assemelhasse ao procedimento terapêutico para reabilitação de disfunções dermato-funcionais. Os resultados obtidos sugerem que o ultra-som terapêutico (pulso contínuo e pulsado), no modelo experimental apresentado, causou apenas aumento dos triglicérides maternos. Não foram observadas alterações nos fetos e placentas de mães expostas a ondas pulsadas, entretanto as ondas contínuas causaram aumento do peso relativo do coração, fígado, rins e pulmões fetais.

\section{Agradecimentos}

À senhora Rosimar Rodrigues de Azevedo, pela colaboração na realização das análises hematológicas. 


\section{Referências}

1. Ullmann D, Reis TM, Steibel V. Princípios básicos da medicina estética. Rio de Janeiro: Letra Capital; 2004.

2. Nava-Ocampo AA, Koren G. Human teratogens and evidencebased teratogen risk counseling: the Motherisk approach. Clin Obstet Gynecol. 2007;50(1):123-31.

3. Guirro E, Guirro R. Fisioterapia dermato-funcional. 3a ed. Barueri: Manole; 2004

4. Pampfer S. Apoptosis in rodent peri-implantation embryos: differential susceptibility of inner cell mass and trophectoderm cell lineages - a review. Placenta. 2000;21 Suppl A:S3-10.

5. Catala M. Embriologia. Desenvolvimento humano inicial. Rio de Janeiro: Guanabara Koogan; 2000.

6. Shoji R, Murakami U, Shimizu T. Influence of low-intensity ultrasonic irradiation on prenatal development of two inbred mouse strains. Teratology. 1975;12(3):227-31.

7. Akamatsu N. [Ultrasound irradiation effects on pre-implantation embryos] Acta Obstet Gynaecol Jpn. 1981;33(7):969-78. Japanese.

8. Hande MP, Devi PU. Effect of prenatal exposure to diagnostic ultrasound on the development of mice. Radiat Res. 1992;130(1):125-8.

9. Child SZ, Carstensen EL, Davis H. A test for the effects of lowtemporal-average-intensity pulsed ultrasound on the rat fetus. Exp Cell Biol. 1984;52(3):207-10

10. Fisher JE Jr, Acuff-Smith KD, Schilling MA, Vorhees CV, Meyer RA, Smith NB, et al. Teratologic evaluation of rats prenatally exposed to pulsed-wave ultrasound. Teratology. 1994;49(2):150-5.

11. Vorhees CV, Acuff-Smith KD, Schilling MA, Fisher JE Jr, Meyer RA, Smith NB, et al. Behavioral teratologic effects of prenatal exposure to continuous-wave ultrasound in unanesthetized rats. Teratology. 1994;50(3):238-49.

12. Iwabe T. Effect of pulsed ultrasound exposure on development of early embryos. Nippon Sanka Fujinka Gakkai Zasshi. 1993;45(2): 113-8.

13. Nepomuceno F, Las Casas L, Peters VM, Guerra MO. Desenvolvimento embrionário em ratas tratadas com Hypericum perforatum durante o período de implantação. Rev Bras Farmacogn. 2005; 15(3):224-8.
14. Hood RD, Miller DB. Maternally mediated effects on development. In: Hood RD, editor. Developmental and reproductive toxicology: practical approach. 2nd ed. London: Taylor \& Francis; 2006. p. 93-124.

15. Gonçalves WLS, Cirqueira JP, Soares LS, Bissoli NS, Moysés MR. Utilização da terapia ultra-sônica de baixa intensidade na redução da lipodistrofia ginecóide: uma terapia segura ou risco cardiovascular transitório? Um estudo pré-clínico. An Bras Dermatol. 2005;80 Supl 3:S352-9.

16. Croxatto H, Ortiz ME, Forcelledo ML, Fuentealba B, Noé G, Moore $G$, et al. Hormonal control of ovum transport through the rat oviduct. Arch Biol Med Exp. 1991;24(3):403-10.

17. Keller KA. Development and reproductive toxicology. In: Keller KA, Jacobson-Kram D, editors. Toxicological testing handbook. 2nd ed. New York: Informa Healthcare; 2006. p. 305-55.

18. Uchida K, Kadowaki M, Nomura Y, Myata K, Miyake T. Relationship between ovarian progestin secretion and corpora lutea function in pregnant rats. Endocrinol Jpn. 1970;17(6):499-507.

19. Waynforth HB. Changes in the volume of rat corpus luteum during pregnancy and after surgical interference with the uterus and placenta. Acta Endocrinol (Copenh). 1971;66(2):296-302.

20. Hood DR. Principles of toxicology revisited. In: Hood RD, editor. Developmental and reproductive toxicology: a practical approach. 2nd ed. London: Taylor \& Francis; 2006. p. 3-14.

21. Souza ER, Guerra MO, Peters VM. Desenvolvimento de préembriões de ratas Wistar da colônia do biotério do Centro de Biologia da Reprodução - UFJF. Bol Centro Biol Reprod. 1997; 16:63-70.

22. Moley KH. Diabetes and preimplantation events of embryogenesis. Semin Reprod Endocrinol. 1999;17(2):137-51.

23. Tyl RW, Marr MC. Development toxicity testing: methodology. In: Hood RD, editor. Developmental and reproductive toxicology: a practical approach. 2nd ed. London: Taylor \& Francis; 2006. p. 201-61.

24. Leite AJ. Quantificação da ruptura celular produzida por Ultra-som em eritrócitos do sangue humano [dissertação]. Ribeirão Preto: Universidade de São Paulo; 1989. 